\title{
Exploration on the Reform of the Mode of Integration of Ethics Teaching
}

\author{
Aijfa Rahnam \\ Assistant Professor, Green University of Bangladesh, M. Ed, Flinders University, Adelaide, Australia \\ Green Business School and Centre of Excellence for Teaching and Learning, Green University of Bangladesh, 220/D, Begum Rokeya \\ Sharani, Dhaka—1207, Bangladesh
}

\begin{abstract}
The conventional education and curriculum focus on degrees and memorization. Does literacy without targeting of gaining moral and ethical wisdom to complete education? Few universities step further and realize the need for incorporating moral education and ethics. They have initiated ethics as an integrated course with all other courses. This study aims to explore the process, areas, impact, and benefits of integration in Teaching Ethics. The study covered a mixed-method approach. Documents review, FGD with teachers, and interviews with experts were conducted. Survey questionnaires were used on students and teachers. About fifty students and thirty teachers were randomly selected from a private university who were entitled to give data in June 2013, December 2014, and February 2020. The survey revealed that students realized the process and level of integration in depth gradually. The ethics course was integrated $62 \%, 55 \%$, and $51 \%$ in teaching methods, materials, and contents respectively that was maintained by interdisciplinary learning curriculum approach. More than three in four participants disclosed that integration reinforced their soft skills learning including critical reasoning, problem-solving, working together and emotional intelligence. About $70 \%$ of teachers including experts found integration creates a positive effect. The integration approach also showed a positive trend to learn another subject, reinforce learning and skills development while academic results might be increased slightly. More than $90 \%$ of graduates revealed that learning from an ethics course helps them to be more ethical in their personal life also and usually those play a vital role in their life holistically.
\end{abstract}

Keywords: Ethics, Ethics Teaching, Integrated Approach, Moral Development.

\section{Introduction}

Education helps the inner growth of human and substantially contributes to society whereas the conventional idea of education which only focuses on memorization and degrees. Does it increase the rate of literacy without targeting necessarily the goal of gaining moral and ethical wisdom? Education with financial security becomes the priority as social structure demands it. The curriculums of some universities step further from this approach and realize the need for practicing humane qualities along with academic areas. The most important human quality that exists within us is conscience or the sense of right and wrong. The study of rightness and wrongness is known as ethics. Ethics refers to well-substantiated standards of right and wrong which prescribe what humans ought to do, generally in terms of rights, fairness, obligations, benefits of the society, or specific virtues(Velasquez, Andre, Shanks, \& Meyer, 2010)[1]. Ethics is the principles and standards of moral behavior that is accepted by society, "right" as opposed to "wrong" which is concerned with moral obligation, responsibility and social justice of all parties involved in the decision making process (Rahman, 2015)[2] whereas, ethics and moral education are deserted in the curriculums. In Bangladesh, according to the medical science and education curriculum, ethics taught as a separate course or subject (Bangladesh Medical \& Dental Council (BM \& DC), December 2008) [3]. However, very few private medical colleges offer ethics as a subject. Correspondingly, private, and public engineering universities have fewer scope than medical colleges. However, some of the private universities incorporated ethics as a cross-cutting topic within the curriculum or at least as an open credit course (UGC Bangladesh, 2019) [4]. On the other hand, in BBA and MBA programs both private and public universities offer Ethics as a subject named Business Ethics (UGC Bangladesh,
2019)[4]. Few universities are offering Ethics as a compulsory course for all undergraduate students. For example, Eastern University has a mandatory credit course for all students where ethical theories are the main parts (Rob, 2014) [5]. As few universities have initiated to offer ethics as an integrated course among all courses, this study aims to explore the ways how this integration works, area of integration, the impact, and benefits of integration in Ethics Teaching. Since learners' academic, personal, moral, and professional developments are the main focus of tertiary level education, students' reaction to this integration process and their developments were investigated too.

\section{Study Rationale}

Very few universities offer ethics as a separate subject with a method of integrated teaching approach. Among them, BRAC University where ethics is taught as an integrated, as well as a mandatory credit course (BRAC University, 2014) [6]. The compulsory courses for this semester are English language courses, Bangladesh Studies, and Ethics \& Culture. The major focus is to maintain integration between courses and activities. Three courses Bangladesh studies, Ethics and Culture, and English are taught here along with various Experiential Learning Activities. One integration strategy is offering a number of extended learning activities in the form of experiential learning in support of classroom activities. These steps allow students to actively participate and learn by doing. Ethics is taught through an integrated approach with the other two courses (Course Outline and Reading Materials of Ethics and Culture Course) [7]. Ethics education has to be integrated which means ethics education needs to be pragmatic (Bowden \& Smythe, 2008) [8].In a study, near one-third of students chosen ethics as an integrated topic with all other courses in their respected discipline, and one fifth percentages learners accepted ethics 
as a mandatory course. People have different personal views on learning ethics. Bowden \& Smyrthe (2008)[8] revealed that teaching ethics in universities and colleges can increase moral cognition and practice of ethical behavior. They also emphasized the role of experiential activities in an ethics course for promoting ethical behaviors. Knowledge of ethics promotes awareness however students believed experience makes people more ethical (Rahman, 2015) [2]. James R. (1982) supported the idea that ethics can be learned through continuing education. Kohlberg's theory of moral development described on Stages of Moral Development and those are Pre-Conventional, Conventional, and Post Conventional. In Tertiary level students are considered to have Post Conventional stage's moral development. The level develops the sense of the right action tends to be defined in terms of general individual rights and standards that have been critically examined and agreed upon by the whole society and the right is defined by the decision of conscience. The emphasis for Kohlberg here is not on whether one answers "yes" or "no", but rather the reasoning behind the answer. Education plays a vital role at this level. Education can modify, redefine, and reshape their moral identity, behaviors, and justification (Kohlberg, 1977) [9]. Consequently, it is high time to define the role of moral and ethics education, explore the mode of ethics teaching, and discover a suitable approach to teach Ethics. From the study about the status of ethics teaching and learning, and their impact, I was interested to discover the issue about teaching ethics through an integrated approach which lead to conduct this research.

\section{Literature Review}

In a society, a high degree of differentiation is characterized. At the same time, a certain degree of coherence and integration is also materialized. This inclination is relevant for diverse subjects in the area of education. Integration in terms of different areas among subjects, activities, and courses, can be the potential to reinforce learning.

For foreign language and second language instructional settings, integrated content and language instruction have played an affluent role in many aspects for the last three decades where academic language includes the concepts, key vocabulary, grammar, and required content. Integrated content and language instruction assess the knowledge, skills, and language of a content area (Sherris, 2008) [10]. The educational system in the United States also is using integrated content and language instruction as an approach (Thomas \& Collier, 2002) [11]. Research findings and experiences of the researchers have assumed, it is possible to integrate language and content successfully and it has a positive impact on students' learning. Specially develop the ability to generate spoken and written language skills, concepts in a content area, proficiency in understanding and producing texts, content-related tasks such as lab experiments, problem- solving, evaluate solutions and collaborate effectively using appropriate academic language (Sherris, 2008)[10].

A second language learning assists by using it as a medium for learning content rather than by studying it as a separate and divergent subject. An integrated approach to fulfill some of the same goals of different courses, content, and language will be interconnected at different times within a lesson and cross-program model. Teachers can help learners gain proficiency in language skills and master content knowledge through this process (Sherris, 2008)[10].

Integrating English and content instruction is a method that integrates English with other subject-matter instruction. This method spotlights learning English over and above using it as a medium to learn mathematics, social studies, science, and other academic subjects. A language can be learned effectively when it is the medium of instruction rather than as a subject (Snow, 2005) [12]. A study on "Integrating English into an Elementary School Life Course" in Chung$\mathrm{Hu}$ elementary school in Taiwan has found regarding how do students feel when the English teacher is also their Life Course teacher where Life Course is composed of science, social studies, art, and music(Chien, December 2003) [13] The finding declared $83 \%$ of students liked the teacher and they found it fun and interesting. This study also indicated $83 \%$ of students had a positive attitude towards the impact of integration. By applying an integrated approach, students will benefit from learning both English and core concepts in integrating English and the Life Course (Chien, December 2003). Integration and interdisciplinary learning have many benefits. Students recognize the links between their learning and real-life /other contexts. Teachers try and fit every subject area into their planning. The integration connects ideas in the curriculum, enhances learning by introducing content from new perspectives, breaks disciplinary boundaries, as well as students, can often draw more meaning and relevance from learning and integrated approach acts as a reinforcement tool (Integration with other Learning Areas) [14]

Short (1991) [15] denotes teachers can regulate their teaching style with the integrated approach for teaching and learning, reducing and adjusting teacher-centered learning. Besides, using cooperative learning, incorporating peer tutoring, designing lessons for students' discovery learning, including information gap activities, adapting traditional English teaching techniques into other content classrooms such as including music, hands-on activities, doing demonstrations, using films or videotapes, supplementary books, role-playing, or portfolio can be recommended for strengthening learning.

Similarly, a study was conducted on the impact of three years' ethics teaching, in an integrated medical curriculum and it revealed that small group ethics teaching can be effective in developing students' normative identification with the profession of medicine (John, Lisa, Alex, \& Jillian, May 2002) [16]. In addition, it has been observed that the overall process of medical education is presented as a form of moral training which just a small piece. Attempt to develop a comprehensive ethics curriculum within the curriculum is required to be functioned (Hafferty \& Franks, November 1994) [17]. Ethics can be integrated with the English and General Education course which also enhances different soft skills and strengthens other learning (Rahman, 2015)[2]. Rahman (2015)[2] in her qualitative and quantitative study revealed that teaching ethics within an undergraduate course can build moral justification and 
implication at least, where integrating ethics with other subjects can be a pragmatic way. Researchers have been investigating ethics teaching since the beginning of the recent decade, therefore preliminary studies are taking place mostly.

A case study discovered that students from different departments found the course ethics stimulated their thinking and learning for sustainable practices both in their personal and professional lives (Biedenweg, Monroe \& Oxarart, 2013)[18]. This study recommends that an ethics course is a functional and potentially significant component to any curriculum determining to prepare future professionals and contributors for achieving a sustainable moral society. In higher education, adopting a course like ethics will benefit the new professionals with a concrete ethical and moral base for making more appropriate, sustainable, and ethical decisions.

Innovative educators concerned with improving student achievement are seeking ways to create rigorous, relevant, and engaging curriculum which is required to be integrated (Drake \& Burns, 2004)[19]. The technique focuses not only on learning English but also on using English as a medium to learn mathematics, science, social studies, and other academic subjects. In fact, integrating English with other subjects has been trendy in the West for years. This language teaching approach aims not only to teach the language as a subject but also to use the target language as a medium for learning academic subjects. A study indicated that eightythree percent of students held positive attitudes toward the fact that their English teacher was also their Life Course instructor and integrating English into Life Course should be done because it provides motivation for students to learn better (Chien, December 2003)[13].

Similarly, Ethics can be taught through the integration approach (Rahman, 2014) [2]. In this case study, Ethics and Culture, English language course, Bangladesh Studies were integrated on the base of course structure (Fakir, 2014) [20]. English was the medium of instruction for those courses. The English course focused on writing academic papers, analyzing reading materials, and developing spoken language and listening skills. Most of the readings or articles used to develop these four skills were very much related to the content of Bangladesh Studies and Ethics courses. Liberation war, political development, the democratic process in Bangladesh, corruption, dilemma, environment, social development, etc. were the most common issues in English comprehension. Those are issues for ethical dilemmas in Ethics and Culture course. The objective of the Ethics Course was to make a student think and behave ethically in personal and professional life. The classes of Ethics focused on the practical issues of morality, values in the light of moral education. Ethics Course also includes knowledge on Gender Education, Women Empowerment, Environment Ethics, Corruption, and other contemporary ethical issues in Bangladesh where Women Empowerment, Environment, Corruption, and Development were the interlinked part of Bangladesh Studies Course. Ethics Course focused on minority rights and liberation war which are also topics for Bangladesh Studies Course. Bangladesh Studies focuses on facts and figures while Ethics and Culture expanded the learning by showing the ethical view and moral judgment. The objectives of the courses highlighted similar areas, contents, and materials used in the classes are reinforced to ascertain effective learning (Fakir, 2014) [20]. Goldie \& Morrison (2002) [21] revealed in their study "The impact of three years' ethics teaching, in an integrated medical curriculum, on students' proposed behavior on meeting ethical dilemmas" that students became more competent and skilled to solve a dilemma which leads them to be an ethical health service provider.

An integrative model was suggested by McDonald [22] in his case in 2004 study where he worked on an integrated approach of an ethics course for undergraduate students within a business degree program. The study investigated the basic questions related to ethics teaching, such as who would be the key person for ethics teaching, how should be it taught, and when. The study came up with a model describing the six-stage processes which were started with a single entry course and moved to an integrated approach oriented course. Similarly, Slocum, Rohlfer, \& GonzalezCanton (2014) [23] found that the integrated microinsertions Ethics course seems more pragmatic and effective for tertiary level students.

Nicholson \& DeMoss (2009) [24] has said that ethics plays an important and collective role in business practice. They also said that teaching ethics is not only teaching an ordinary course for employment, rather it is a course to teach as our social responsibility. This mixed-method study recommended an integrated approach to ethics teaching for undergraduate students.

\section{Research Question}

The following questions had been considered, regarding exploring the integrated approach of ethics teaching.

1) Are students and teachers aware of the integrated approach of Ethics teaching?

2) What are the areas of integration for teaching Ethics?

3) How Ethics is been integrated with other courses?

4) What are the impacts of the integrated approach in teaching Ethics?

5) What are the benefits of integrating ethics with other courses?

\section{Methodology}

The study covered a mixed-method approach considering a particular university as a case since ethics is taught by an integrated approach there. For the qualitative approach, document review, FGD with teachers, and interviews with experts were conducted. And for the quantitative approach, survey questionnaires (Pre-Post Test Mood) were used on students and teachers. In this study, for collecting data, 50 learners were randomly selected from the summer 2013 batch who were entitled to give data three times (once studying ethics course, another 1 year later after completing the course and one while they are in professional life). Afterward, 30 faculty members who were associated with RS were selected by simple random sampling. One focus group discussion (15 members) had conducted with teachers. Two experts' interviews were also conducted. Pre-test Post- 
test mode of the survey was set and conducted in order to justify the real impact of integration. A separate questionnaire has been applied to collect data from teachers. Both the questionnaires had 10 questions in combination with multiple choices, open-ended, and Likert scale questions. To understand and analyze the level and process of integration, the author reviewed relevant documents such as course reading materials, supplementary materials of those courses, text for activities, students' reflection paper and documents on course interdisciplinary integration, manual, University Annual reports and necessary documents ( meeting minutes, committee reports, etc.). To have primary information, the researcher also got the opportunity to involve with the integration process for 2 years. SPSS version 20 computer package and Microsoft Office Excel 2010 were used to analyze and interpret the data.

\section{Findings, Analysis, and Discussion}

Data collected from 80 respondents were used for quantitative analysis. Among the respondents, 50\% were male and $50 \%$ were female participants. It has been discovered through the survey that at the beginning students could not realize the process and level of integration among courses and activities in depth. Afterward, students realized better. Students also have mentioned the areas of integration that were content (topics are related to Bangladesh), the mission of the university, skills (creativity, problem-solving, critical thinking, leadership, interpersonal communication, emotional intelligence, and English language skill), teaching methods and means. From the following tables, it is noticeable that less than half of the participants were unaware of the integration during their semester, whereas $30 \%$ were not sure about the presence of interdisciplinary integration after one year.

Table 1: Awareness about Integrated Approach of Ethics

\begin{tabular}{|c|c|c|c|}
\hline Students' Awareness & $\begin{array}{c}\text { Teaching } \\
\text { studying } \\
\text { Ethics } \\
\text { Course }\end{array}$ & $\begin{array}{c}\text { Post-test- } \\
\text { One year } \\
\text { after doing } \\
\text { Ethics } \\
\text { Course }\end{array}$ & $\begin{array}{c}\text { Post-test after } \\
\text { graduation } \\
\text { while in } \\
\text { Professions }\end{array}$ \\
\hline $\begin{array}{c}\text { Integration Ethics with } \\
\text { other course }\end{array}$ & $28 \%$ & $46 \%$ & $63 \%$ \\
\hline Not sure & $36 \%$ & $30 \%$ & $25 \%$ \\
\hline Don't understand & $5 \%$ & $2 \%$ & $0 \%$ \\
\hline Not Integrated & $6 \%$ & $4 \%$ & $0 \%$ \\
\hline $\begin{array}{c}\text { Integrated but don't } \\
\text { understand how }\end{array}$ & $25 \%$ & $18 \%$ & $12 \%$ \\
\hline
\end{tabular}

Teachers have highlighted teaching ethics by an integrated approach in FGD. Teachers were briefed about the integrated approach and it's maintaining the processes by the guidance of peers and supervisors. Ethics teachers also took other activities' classes and became guest teachers for other courses. About $14 \%$ of teachers revealed this area for integration. Awareness of integration has been gradually increased by getting mature in terms of time and age.

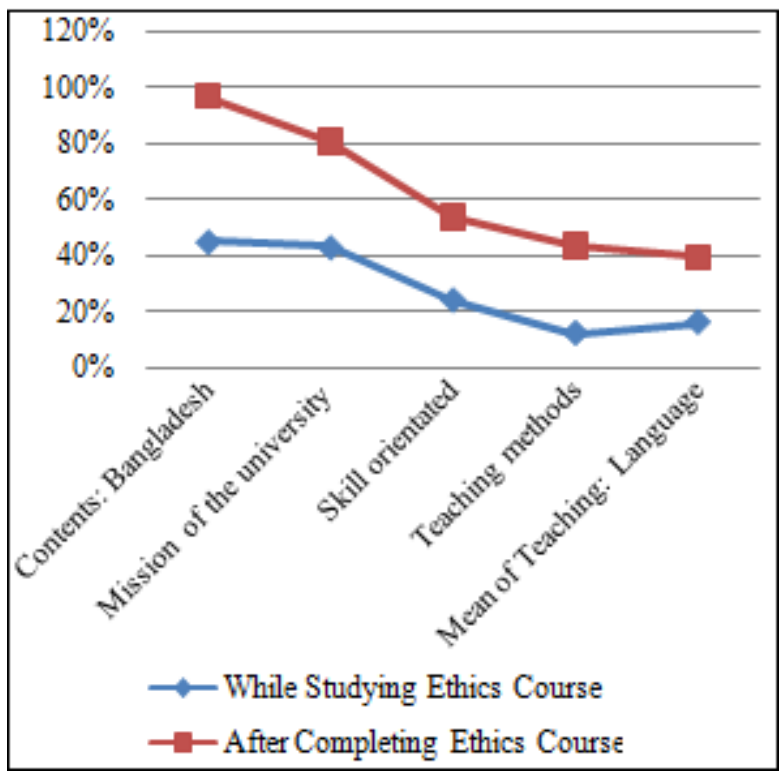

Figure 1: Areas of Integration

Figure 1 presents the areas of integration. It is clearly seen that five major areas were considered while integrated Ethics Course with other courses and activities where integration through "content" had the highest percentages. The arenas of integration among courses and activities have mentioned by the teachers in the survey and FGD were illustrated in the line chart including students' views. Participants have said that integration of ethics in terms of contents, curriculum, supplementary materials, and teaching methods most. Some of the teachers mentioned block teaching for ethics teaching (one teacher for all subjects). After completing the course, students realized more about the level of integrations in different areas over a period of time.

Alternatively, Figure 2 shows only teachers' view.

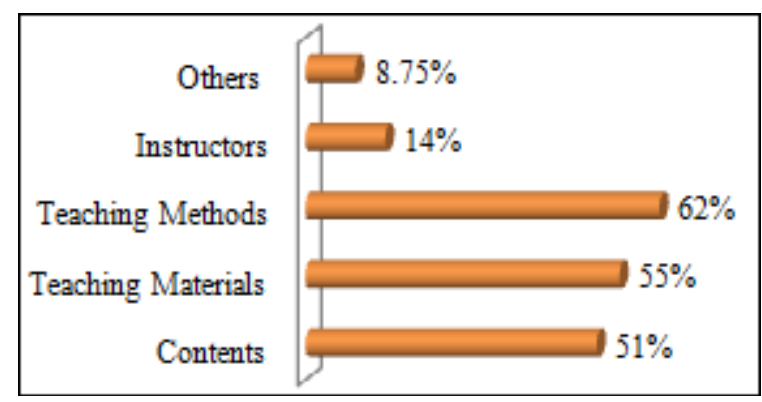

Figure 2: Areas of Integration (Teachers' View)

Ethics and Culture course was integrated 62\%, 55\%, and $51 \%$ in teaching methods, materials, and contents respectively. For example, a case study was the most popular method for teaching ethics which was also applied for other courses. A documentary (The Promise Land) was used as supplementary material for Ethics and Bangladesh Studies course. Similar types of contents were introduced in the curriculum of those courses. For example, Human rights were a common topic of English Language, Ethics, and Bangladesh Studies course. However, different courses had individual aspects.

Qualitative and qualitative data disclosed that experiential learning activities were integrated with the ethics course as 
well. A list of experiential learning activities from where students choose their preferred ones among Debate, Drama, Spelling Bee, Happy Reading, Creative Writing, Recycling, Hydroponic Vegetable Cultivation, and Photography. Objectives of the activities and courses were interrelated which were basically focused on soft skills developments along with empathy (creativity, problem-solving, critical thinking, leadership, interpersonal communication and English language skill, presentation, socialization skills, emotional intelligence, etc).

From the review of the documents, it has been noticed that skills developments were the major component of all three courses and activities. In the Ethics course, critical thinking was practiced as students evaluate and bring out the righteousness and depravity of the voluntary human behavior in the context of our cultural background. Moreover, the English language was integrated into two other courses as the medium of instruction and discussion. Bangladesh Studies provides factual knowledge along with the analytical skill that helps students to get factual knowledge and critically analyze and appreciate the history, politics, and economy of Bangladesh. In the English course, a critical analysis was also highlighted as students analyze different reading texts and answer opinion-based questions. Moreover, the acquisition of language skill is another component which was emphasized in all the courses. Class lectures and discussions in the classrooms for all the 3 courses were in English. Students were constantly inspired by all the teachers of the courses to apply English inside and outside of the classroom. Class presentations were integrated with all the three courses and presentations were done in English. Objectives and learning outputs were determined in a way so that students use their creative ideas to come to a conclusion or to evaluate multiple issues. Ethics course endorses creativity while learning about historical perspectives of Ethics and different ethical theories, applying those theories in coping with different ethical dilemmas of their lives and understanding the notion of right and wrong to gain a strong moral education. And English course requires students to evaluate a text and answer opinion-based questions, to write paragraphs, essays, and response paper by following proper structure and contents. Bangladesh Studies allowed students to use their creativity while evaluating and commenting on learning political development of the ancient, medieval, and colonial and postcolonial periods, social structures, diverse cultural identities, and tensions arise between different groups.

All the experiential learning activities were integrated with the contents learned in the classroom. In the Bangladesh Studies and Ethics textbook, it was mentioned that as a part of their course, students perform a drama on different recent moral dilemmas they face and they also propose the solution for that. The presentation was a common classroom activity for all three courses. Presentation skills as an experiential learning activity complement classroom learning. Documents revealed that interactive discussion and participatory classroom were common practices in all three courses. Group work, pair work individual projects, group presentation were assigned to the students to work together. The leadership skill and interpersonal communication get enhanced. As courses were integrated, teachers meet with each other and discuss the effectiveness of this process. The weekly reflection meetings were the platform where teachers evaluate the materials, classes, and how the process of integration was working. Therefore, it is clearly addressed that the integrated approach of ethics teaching was maintained by the interdisciplinary learning curriculum of those courses, mission of the university, and direct monitoring by weekly meetings, process of evaluation, and continuous development.

Soft skills related to their personal and professional life were developed due to integration which seems a vital impact of learning ethics through integration. A student said that

Impact of Ethics course in our life is huge, as a being a professional I have to make decisions in my office as well as at home. The ethics course has enriched our way of thinking.

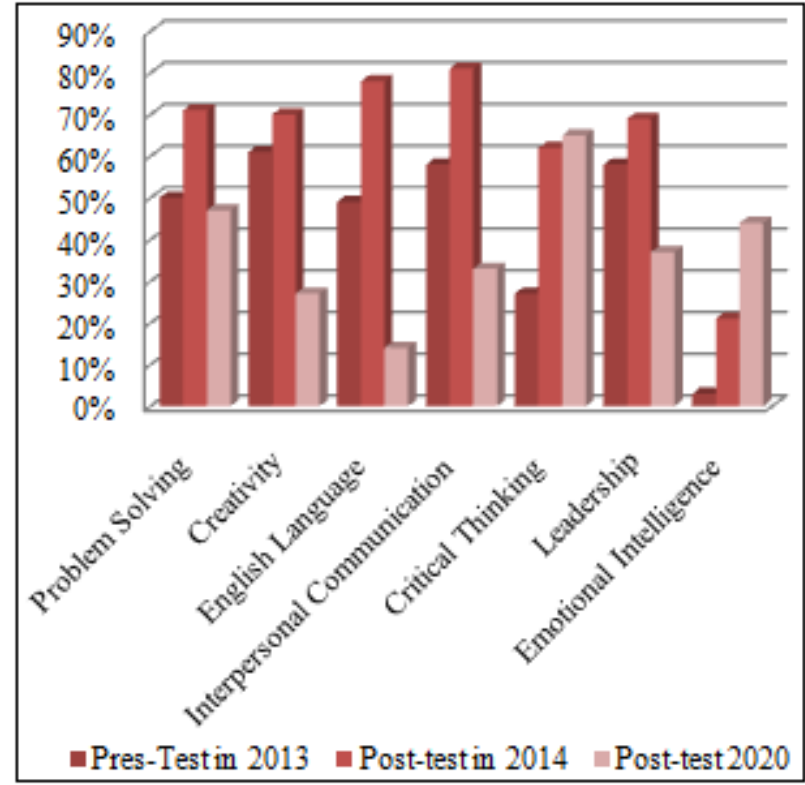

Figure 3: Soft Skills' Development through Integration

The above chart illustrates a comparative study among the students from 2013 to 2020 regarding the developments of their soft skills. Students have mentioned in December 2014 after completing one year of ethics course that integration reinforced their skills by $72 \%, 70 \%, 78 \%, 81 \%, 62 \%$ and $68 \%$ on Problem-Solving, Creativity, Language, Interpersonal Communication, Critical thinking, and Leadership skill respectively and the rates were higher in post-test in 2014 than in 2013and in 2020.

In the 2020 survey, students argued that only Emotional Intelligence and Critical Thinking are the most significant and relevant soft skills which were developed through integration properly. The bar chart (figure 3) shows a sharp and gradual increase over time of those soft skills. It seems that students got more realizations and understandings about the related soft skills that were developed by ethics course when they are working in a profession or settle in their life in 2020. The participants of summer 2013 who are professionals or entrepreneurs nowadays have said that $73 \%$ of them find ethics course guiding them to be moral in professional life. Most of them $(60 \%)$ have suggested an 
integrated approach of teaching ethics than teaching ethics as an individual course $(20 \%)$ or at home (9\%) only.

Moreover, more than $90 \%$ of graduates revealed that learning from the ethics course helped them to be more ethical in their personal life also, and usually those play a vital role in their life. An anonymous graduate has said (2020) that

The ethics course has a great role in my life. At that point in time when we were growing up, a course like Ethics added great value. It has helped me to see the borderer version of life and everything to see broader than before. In short, in our busy lives, this course has taught us how to deal with life, how to think, and how to deal with people.

From the teachers' point of view, processes, and components of integration facilitated to improve soft skills. About $88 \%$ of teachers agreed about the importance of integration among courses and between activities and courses. Furthermore, $70 \%$ of teachers found, the integration creates a positive effect on students' learning. Courses were integrated because this brings corroboration and optimum practice. Integration is being maintained between courses and activities to maximize the success of university goals as well.

Moreover, teaching ethics through an integrated approach or integration also disclosed some benefits. The following bar chart in figure 4 demonstrates that integration reinforced learning, skills acquisition and ability to work together. The integration approach also showed a positive trend to learn another subject. Nevertheless, students' academic results or grades might be increased slightly.

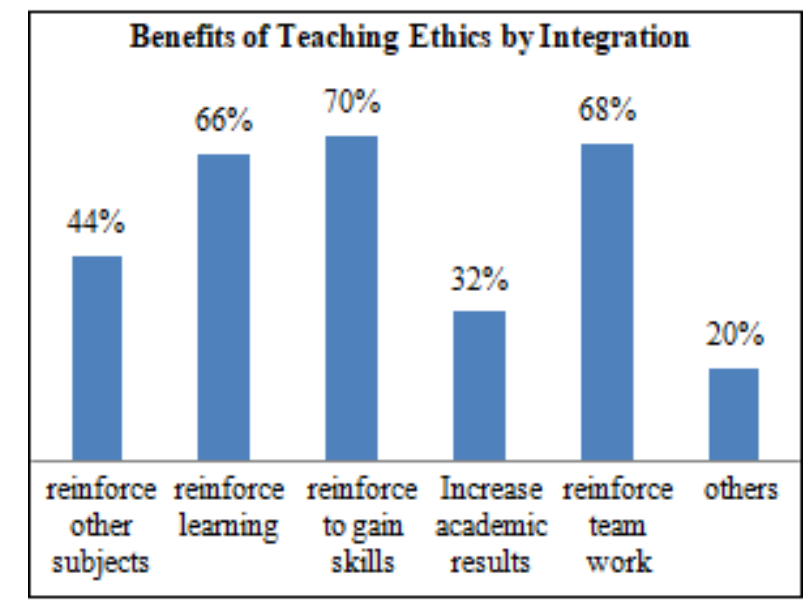

Figure 4: Benefits of Teaching Ethics through Integration

A student mentioned in 2020 that

Well to be honest, before this course I had no idea that this could be a subject. It has a huge way to enlighten the inner self of someone and by learning it someone can get better at controlling emotion while taking decisions. This actually changed the way I looked into the world and I love it.
The above comment straightforwardly reflects the true benefits of an integrated ethics course. It seems the ultimate achievement of the outcomes of the ethics course.

\section{Conclusion}

In the education system, all the aspects of developments of a human are required to address along with moral developments. In childhood, family and parents take part in building our morals with a sense of rightness and wrongness. However, gaining knowledge of right and wrong or Ethics and practicing Ethics are reinforced by the education which is also mentioned by Kohlberg in his theory of moral development. Educational institutes, system, and curriculum need to uphold the presence of moral education and practicing ethics. Many debates are raised on learning and teaching by a course or within the classrooms. According to Aristotle Ethics cannot be taught in the classroom the same as virtue. The modern concept says classroom teaching can influence to learn Ethics and practice it (Rob, 2014) [5] Different scholars are studying Ethics teaching and it's future aspects. Learners are interested to learn Ethics within the education system from school to university level (Rahman, 2015) [2]. One of the students of this study robustly mentioned that

If we have don't have an ethics course, what do we ever have? It's been so many years I have gained several degrees at home and abroad but was not fortunate enough to go through another course like ethics.

Suitable and accurate processes of teaching Ethics are necessary to form that to lead us for more studies on this arena (Fakir, 2014) [20]. Teaching Ethics at the tertiary level may influence learners' self- realization, rational justification, and reflections of morals and ensure their moral complete development. The interdisciplinary approach or integrated approach of learning may applicable to address learners' moral development. For example, English is a tool of communication rather than a language only and students learn English more when it is integrated with other subjects (Chien, December 2003)[13]. Moral development is required to deal with the education system by means of integration as well.

\section{References}

[1] Velasquez, M., Andre, C., Shanks, T., \& Meyer, M. (1987). Can ethics be taught? Retrieved July 30, 2015, from Issues in ethics: http://www.scu.edu/ethics/practicing/decision/canethic sbetaught.html

[2] Rahman, A. (2015). Future Prospect Of Ethics Teaching: A Comparative Study. International Journal of Education \& Applied Sciences Research , 28-37.

[3] Bangladesh Medical \& Dental Council (BM\&DC). (December 2008). Module on Teaching Health Ethics in Undergraduate Medical Education in Bangladesh.

[4] Bangladesh, U. G. (2019). University Grants Commission of Bangladesh. Retrieved March 25, 2020, 
from Private University: http://www.ugcuniversities.gov.bd/private-universities

[5] Rob, P. D. (2014, August 18). Ethics Course at Eastern University. (A. Rahman, Interviewer)

[6] BRAC University . (2014). Retrieved June 24, 2015, from Course Details : http://www.bracu.ac.bd/academics/departments/mathe matics-and-natural-sciences/bachelor-sciencebiotechnology/course-details

[7] Course Outline and Reading Materils of Ethics and Culture Course . (n.d.). BRAC University . Dhaka .

[8] Bowden, P., \& Smythe, V. (2008). Theories on Teaching and Training in Ethics. Electronic Journal of Business Ethics and Organization Studies , 19-26.

[9] Kohlberg, L., \& Hersh, R. H. (1977). Moral Development: A Review of Theory. Theory into Practice, 53-59.

[10] Sherris, A. (. (2008). Integrated Content and Language Instruction. Washington: Center for Applied Linguistics .

[11] Thomas, W. P. \& Collier, V. P. (2002). A national study of school effectiveness for language minority students' long-term academic achievement, Santa Cruz, CA: Center for Research on Education, Diversity $\&$ Excellence.

[12] Snow, M. A. (2005). A model of academic literacy for integrated language and content instruction, Handbook of research in second language learning (pp. 693-712), Mahwah, NJ: Erlbaum.

[13] Chien, G. C.-W. (December 2003). Integrating English into an Elementary School Life Course. The Internet TESL Journal , 12.

[14] Integartion with other Learning Areas. (n.d.). Retrieved September 1, 2015, from Flinders University : http://ehlt.flinders.edu.au/education/DLiT/2003/group1 3/integration.htm\#top

[15] Short, D. (1991). Integrating Language and Content Instruction: Strategies and Techniques. NCBE Program Information Guide Series, no 7.

[16] John, G., Lisa, S., Alex, M., \& Jillian, M. (May 2002). The impact of three years' ethics teaching, in an integrated medical curriculum, on students' proposed behaviour on meeting ethical dilemmas. Medical Education , 489-497.

[17] Hafferty, F. W., \& Franks, R. (November 1994). The hidden curriculum, ethics teaching, and the structure of medical education. Journal of The Association of American Medical Colleges, 861.

[18] Biedenweg, K., Monroe, M. C., \& Oxarart, A. (2013). The importance of teaching ethics of sustainability. International Journal of Sustainability in Higher Education, 6-14.

[19] Drake, S. M., \& Burns, R. C. (2004). Meeting Standards Through Integrated Curriculum. Association for Supervision and Curriculum Development (ASCD)

[20] Fakir, P. S. (2014, September 23). Ethics Teaching . (A. Rahman, Interviewer)

[21] Goldie, J., Schwartz, L., McConnachie, A., \& Morrison, J. (2002). The impact of three years' ethics teaching, in an integrated medical curriculum, on students' proposed behaviour on meeting ethical dilemmas. Medical education, 36(5), 489-497.

[22] McDonald, G. M. (2004). A case example: Integrating ethics into the academic business curriculum. Journal of Business Ethics, 54(4), 371-384.

[23] Slocum, A., Rohlfer, S., \& Gonzalez-Canton, C. (2014). Teaching business ethics through strategically integrated micro-insertions. Journal of Business Ethics, 125(1), 45-58.

[24] Nicholson, C. Y., \& DeMoss, M. (2009). Teaching ethics and social responsibility: An evaluation of undergraduate business education at the discipline level. Journal of education for business, 84(4), 213218 . 